\title{
The Impact of Luckin Coffee's Negative News on Its Stock Price and the Financial Market
}

\author{
Chak ho Chau ${ }^{1, *}$ \\ ${ }^{1}$ University of Illinois Urbana- Champaign \\ *Corresponding author.Email: chchau2@illinois.edu
}

\begin{abstract}
Past studies have found that financial news has a relationship with stock prices. Bad news has negative impact on stock prices, but the type of bad news also matters. When a stock is shocked by a natural disaster, a dip of its stock price is only temporary; when it is shocked by a scandal event, such dip can be permanent and severe. Depending on the type of news, investors have different trading strategies; they may choose to hold the stocks that are shocked by a natural disaster and sell the stocks that are shocked by a scandal event. This paper focuses on the impacts of Luckin Coffee's scandal event on April 2020 and the outbreak of COVID-19 on March on its stock price, its top competitor Starbucks' stock price, and on the Nasdaq index. I collected stock prices of Luckin Coffee, Starbucks, and Nasdaq index from Yahoo! Finance from July 2019 to July 2020. By using regression analysis, the result shows that though the scandal event affected Luckin Coffee's stock price severely, causing it to be in an irreversible situation, the impacts on Starbucks and Nasdaq are limited; the dip shown in Starbucks and Nasdaq on March is just due to the hit by the global pandemic, COVID-19.
\end{abstract}

Keywords: Financial news, Luckin Coffee, stock price

\section{INTRODUCTION}

It is common that financial news may influence investors' decisions of trading one firm's stocks. When there are two types of negative news: one could be due to natural disaster and the other could be due to fraud, it is important to identify each type of news' impact on stock prices to help investors to make better decisions. As natural disaster could eventually be recovered, investors may consider holding the stocks. However, if the news is due to a fraud, it is unlikely for that stock price to recover, and investors may consider selling the stock.

For some industries, due to the effect of oligopoly, a downfall of one company may have a severe impact on the whole industry and its top competitors. In an oligopoly market, there are only a few competitors, which means that each company's market share is so large that any rise or down of its stock price can shake the whole market at an intense level. In this paper, I focus on how much damage the negative news causes to its stock price, and what kind of impact does it have on its competitors and the financial market. Is the impact positive or negative?
There are other papers that study the relations between financial news and stock prices. With the advancement in many methodologies such as textual analysis, there is a growing literature on this topic. Boudoukh et al [1] suggest that stock prices have a strong relation with financial news; more specifically, on news days, the volatility is much higher. By using computational linguistic method, Antweiler and Frank [2] are able to come up with the idea that an increase in the number of messages can result in a rise in stock volume and volatility. Chan [3] finds out that both good and bad news have some degree of impact on the stock returns, bad news' impact is stronger than good news. However, none of these papers mentions the effect of one company's negative news on its competitors' stock price, and that's how this paper can contribute to the financial literature.

The objective of this study is to understand the impact of Luckin Coffee's negative news on its own and competitor's stock prices, and on the financial market. In order to answer these questions, this study investigates a well-known scandal event of Luckin Coffee, a rising startup company from China with a fast-growing IPO. On April 2nd, 2020, it was found out by an internal investigation that Luckin Coffee fabricated its sales 
transactions. Such event is so harmful to Luckin Coffee that its stock price had a severe dip in April and never recovered. Moreover, it might influence more than just Luckin Coffee itself; as Luckin Coffee's top competitor, Starbucks' stock price may also be affected. The month of April is also when the outbreak of COVID-19 started, which may also have an impact on these stock prices. We choose this event as it is a natural testbed for us to understand how natural disaster and a firm's scandal event affect stock prices differently.

I collected data of Luckin Coffee, Starbucks and Nasdaq index from Yahoo! Finance from July 2019 to July 2020 where the scandal event of Luckin Coffee happened on April 2nd, 2020. I used regression analysis to analyze the difference between before and after the news impact hits stock price and Nasdaq index. I found that the negative news had the most impact on Luckin Coffee, which is shown by its drop of stock price after the news came out, a $24.596 \$$ reduction. In addition, the result suggests that the negative news had limited impact on Starbucks, which can be seen by its regression coefficient, a $10.561 \$$ reduction. Unlike the other two stock prices, the news did not have any negative impact on Nasdaq index, since its regression coefficient is positive. I plotted the time series of Luckin Coffee, Starbucks, and Nasdaq index. The figures show that Luckin Coffee never recovered from its scandal event, which can be proven by its L-shape stock price. Starbucks and Nasdaq have almost identical time series plots - both had a severe dip during the pandemic of COVID-19, and both recovered from this event.

I organize this paper in the following way. In next section, I summarize some other studies that also focus on the relation between negatives news and stock prices. After the literature review, I give a background review of Luckin Coffee. In Section 4, I show the data that I' ve collected and the results. In Section 5, I conclude the study.

\section{LITERATURE REVIEW}

My paper is related to the research area that studies the relationship between financial news and financial returns. Similar to my research, Boudoukh et al's [1]finding suggests that financial news is strongly related to stock prices. The authors believe that the past findings have done a poor job of relating financial new to stock prices because in the past, researchers had no tool to filter out the unnecessary information from news, which results in a chaotic database that is crucial to the researches. Nowadays, with the advancements in textual analysis, Boudoukh et al [1] are able to use such methodology to further identify relevant/useful information. The authors find that, in addition to the proven idea that stock price and financial news are closely connected, volatility is higher identified on news days. This paper does not mention the impact of financial news on its competitor's and the whole market's financial returns, which is studied in this paper.

Moreover, Antweiler and Frank's [2] results are also related to stock market's volatility. Their study tries to examine whether the information on the financial message board is just noise or not- to see if the information can impact the stock market. By using computational linguistic method, they examine the bullishness of messages posted on Yahoo! Finance and Raging Bull. Their study finds out that although the information and the number of messages cannot directly predict stock returns, it is a fact that an increase in the number of messages can result in a rise in stock volume and volatility.

If financial news can be divided into two categories, good news and bad news could have different impacts, or in other words, the level of impact they have on stock market can be different. Chan's [3] finding is really interesting, because unlike the other two studies introduced above, he initially hypothesized that there will be no abnormal impact on stock market after a related financial news being released. He finds out that financial news has direct connection with stock returns. By comparing two sets of stocks with similar monthly returns, one with related public news and one without any; and he finds out that although both good and bad news have some degree of impact on the stock returns, bad news' impact is stronger than good news. The reason that I not only bring up the relation between news and stock market but also the difference between good and bad news is that my research's targeted subject is Luckin Coffee, which was affected by negative news. Such idea can be viewed that people normally under-react to good news but over-react to bad news.

\section{EMPIRICAL CONTEXT}

I choose the empirical context to focus on Luckin Coffee and its recent financial news. I chose Luckin Coffee to be the main focus of this research because it is a typical example of how negative financial news can harm a company in the stock market. For the past decade, Starbucks has been the main source of coffee for Chinese people with high quality of coffee and comfortable atmosphere for costumers. Although there are a few other competitors in the market, such as Maan Coffee and Costa, Starbucks remained as the top seller. However, the high prices of Starbucks coffees have always been the main criticism from the public, in addition to the problem of slow delivery. But everything changed on October 2017 when the first Luckin Coffee started in Beijing. Unlike Starbucks, one thing that makes Luckin coffee special is its constant offers of coupons and discounts that make the prices of coffees low. Luckin Coffee also took advantage of China's well-developed delivery system and technology. Instead of simply being a coffee shop, Luckin Coffee allows customers to order coffee online 
via its app with cashless payment and without having to wait at the front desk. For online delivery, Luckin Coffee provides a thirty-minute delivery guarantee, which perfectly fits the fast pace life in modern cities in China.

With these two advantages over Starbucks, Luckin Coffee quickly became a well-known name in China. With the backing of multiple investment companies such as BlackRock, Luckin Coffee was able to vastly expand within a short period of time, making it around two-thirds the size of Starbucks in China. On May 17th, 2019, Luckin Coffee priced its initial public offering at $17 \$$ per share on Nasdaq.

In December 2019, with 4570 stores, Luckin overtook Starbuck's top seller position, and became the largest coffee chain in China. In addition to the stores that are just a few feet away from Starbucks stores, on January 18th, 2020, Luckin Coffee launched two types of vending machines, called Luckin Coffee EXPRESS and Luckin Pop MINI, in order to further take over the market. But just as things were going well with Luckin Coffee, a dramatic turn occurred. On April 4th, 2020, an internal investigation had shown its chief operating officer, Jian Liu, and other employees fabricated sales transactions, resulting a $81 \%$ loss of shares. This scandal event wiped out 5 billion dollars off its market capitalization. Such downward trend was also resulted by 98 pages of report provided by the short seller company Muddy Water. In this paper, I study how this event affects Luckin Coffee and Starbucks' stock price and the whole Nasdaq index.

\section{DATA, MATH, AND EQUATIONS}

I obtained my data from Yahoo! Finance, a website that provides financial news and data. The reason for using this platform as my collection of data is that it is a well-known website with 70 million active daily users per month. The platform provides daily updates of data, which is good source for me to collect and analyze.

I collected the daily close prices of Luckin Coffee, Starbucks, and Nasdaq from July 2019 to July 2020. This range of date covers both the scandal event of Luckin Coffee and the COVID-19 pandemic. Within this date span, Luckin Coffee experienced the expansion and the downfalls due to two events. From July 2019 to December 2019, the stock price of Luckin Coffee raised, where it took over Starbucks' top position in China as the top seller. From December 2019 to July 2020, the data show the timeline of COVID-19 that had a negative impact on the whole stock market from the start of March to April and the fall of Luckin due to the scandal event from April 2nd, 2020 to ever since then. The full data span shows the overall range of date shows the full history of Luckin Cofee, from reaching to the top position of coffee chain to becoming a fraud.

As Luckin Coffee's number one competitor, it is important to see how Starbucks' stock price was affected.
I hypothesized that after Luckin Coffee's scandal, Starbucks' stock price will go up. The stocks may also be affected by the COVID-19 pandemic. Both two stocks are on the Nasdaq index, which makes the comparison easier to see.

I also used a bigger picture to compare Starbucks and Luckin Coffee, using Nasdaq, which is a stock market index that includes almost all stocks listed on the Nasdaq stock market. I chose to use this index because it is known as the most-followed index in the United States. I want to see if the negative news of Luckin Coffee is related to the pandemic. In other words, is the fall of Luckin Coffee's stock price purely due to the scandal event, or if there are other factors that pushed this fall?

By using the data provided by Yahoo! Finance, I collected 6 categories- high, the highest stock price; low, the lowest stock price; close, the price at the point when the stock market ends each day; adjusted close price, the close price that is adjusted after accounting for any corporate actions; and volume, the amount of trades. In total the number of observations is 253 .

If we look closely at the mean and maximum of Luckin Coffee, we can see that the difference between them is large, which suggests that the volatility of this stock is high comparing with Starbucks. The standard deviation can also be an indicator that Luckin Coffee's stock price has a high volatility, which can potentially be due to the scandal event. Comparing with Luckin, Starbucks' volatility is relatively low, which is likely due to the absence of negative news that can damage the stock price.

In Figure 1, we can see that Luckin Coffee's stock price has been dipping since the beginning of March. If we divide the graph into two separate parts, each part' s downfall can be explained differently. From the beginning of March to April 2nd, the dip of Luckin Coffee's stock price is due to the pandemic of COVID19; ever since then, due to the scandal event, Luckin Coffee's stock price presents a L-shape, and it never recovered.

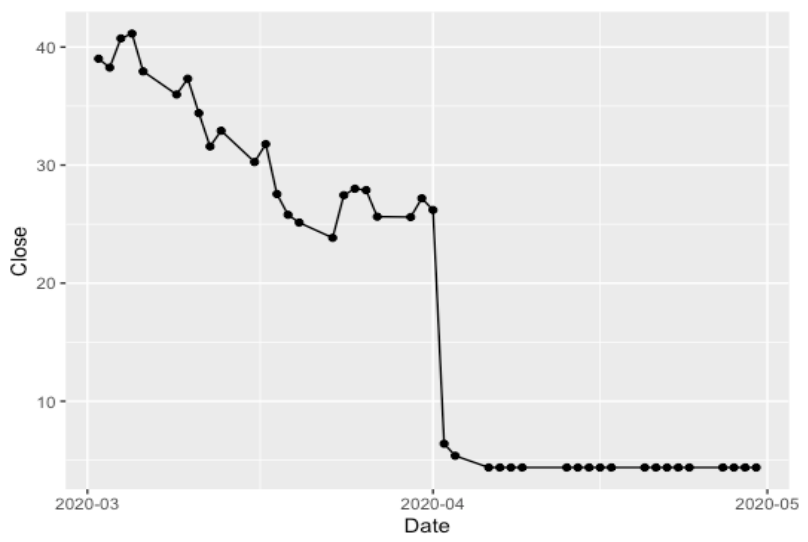

Figure 1 Time Series Plot of Stock Price for Luckin Coffee 
In figure 2 and 3, we see the time series plots of Starbucks and Nasdaq; both graphs show a significant dip from early March to mid-March. Such severe drop of stock prices is due to the effect of COVID-19, but soon recovered. The two figures have identical ups and downs, which, unlike Luckin Coffee, was not affected by the scandal event.

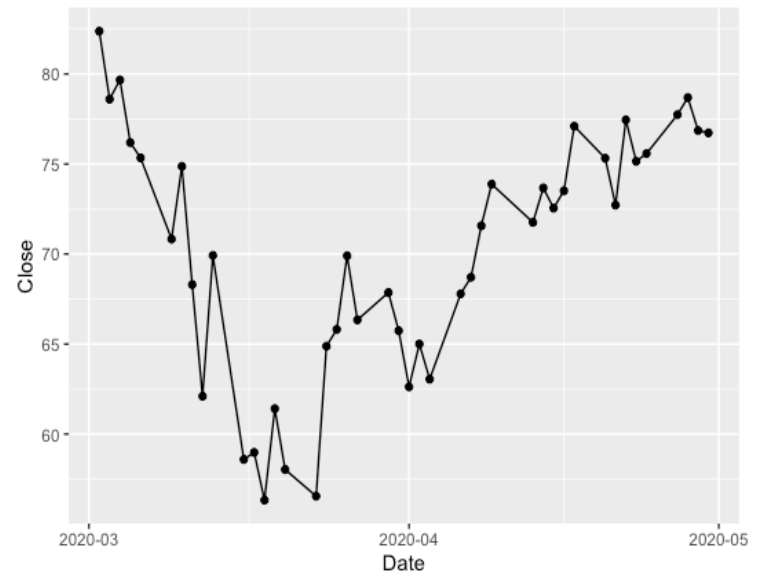

Figure 2 Time Series Plot of Stock Price for Starbucks

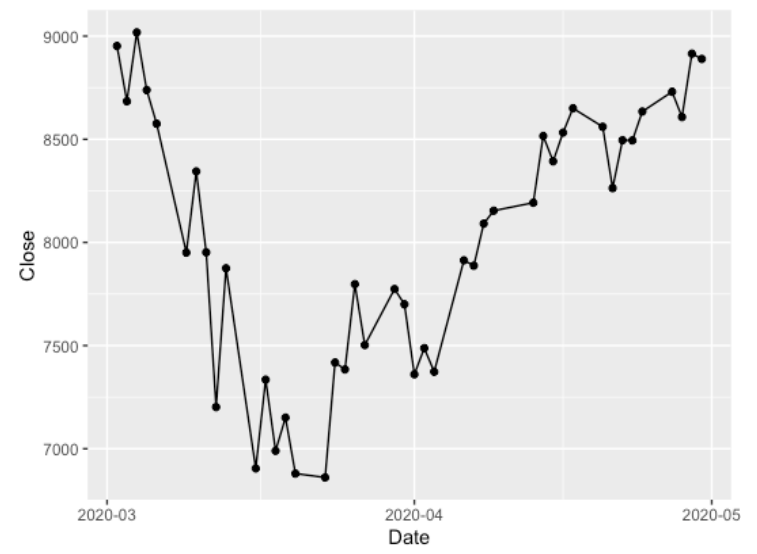

Figure 3 Time Series Plot of Stock Price for Nasdaq
In the beginning of March when COVID-19 started to grow in the U.S, the whole stock market was negatively affected, both Starbucks and the whole Nasdaq index showed a dip of stock prices, which suggests that the pandemic has affected the market in a global scale. After the hit from the pandemic, the overall stock market recovered. Therefore, the downfall of Luckin Coffee after Nasdaq and Starbucks hit the lowest would be due to the negative news. The L shape of Luckin Coffee's stock price is disastrous because it never recovered, which explains why the Min of volume of Luckin Coffee is 0 , an abnormal trading pattern; and Starbucks was not benefitted from Luckin Coffee's downfall.

Table 4 shows the regression result where the function can be expressed as $Y=\alpha+\beta x+$ error; in order to see how much the stock price would change, a mathematical method can clearly show the difference between before and after the news, which is the scandal event of Luckin Coffee that happened on April 2nd. Breaking down the function to individual pieces, $\alpha$ is the constant value and $\beta$ shows how much the stock price will change after the news is released; $\mathrm{Y}$ is the stock price and $\mathrm{x}$ is the occurrence of the scandal event that can be either 0 , before the news, or 1 , after the news.

From the given table 4 , it is clear that the news did not affect Nasdaq's stock index, which can be seen at Nasdaq's b value 767.558 - it is positively correlated with the overall closed price, a contrast with Luckin Coffee's negative value -24.596 . Starbucks was affected by the news since the $b$ value is also negative, -10.561 , but not as severe as Luckin Coffee.

Table 1 Summary of Statistics for Luckin Coffee

\begin{tabular}{|c|c|c|c|c|c|c|c|}
\hline Statistic & N & Mean & St. Dev. & Min & Pctl(25) & Pctl(75) & Max \\
\hline Open & 253 & 21.746 & 12.615 & 1.380 & 18.150 & 31.260 & 49.150 \\
\hline High & 253 & 22.564 & 13.121 & 1.380 & 18.830 & 32.500 & 51.380 \\
\hline Low & 253 & 20.927 & 12.126 & 1.160 & 17.840 & 30.100 & 49.060 \\
\hline Close & 253 & 21.749 & 12.669 & 1.380 & 18.210 & 31.470 & 50.020 \\
\hline Adj.Close & 253 & 21.749 & 12.669 & 1.380 & 18.210 & 31.470 & 50.020 \\
\hline Volume & 253 & $17,072,577.00$ & $37,960,492.000$ & 0 & $2,266,200$ & $14,511,400$ & $293,601,30$ \\
\hline
\end{tabular}


Table 2 Summary of Statistics for Starbucks

\begin{tabular}{|c|c|c|c|c|c|c|c|}
\hline Statistic & $\mathrm{N}$ & Mean & St. Dev. & Min & Pctl(25) & Pctl(75) & Max \\
\hline Open & 253 & $8,592.356$ & 705.642 & $6,847.280$ & $8,091.680$ & $9,177.150$ & $10,130.830$ \\
\hline High & 253 & $8,660.806$ & 696.245 & $6,984.940$ & $8,146.150$ & $9,235.200$ & $10,221.850$ \\
\hline Low & 253 & $8,523.611$ & 716.810 & $6,631.420$ & $8,046.800$ & $9,059.380$ & $10,112.440$ \\
\hline Close & 253 & $8,598.762$ & 708.425 & $6,860.670$ & $8,098.380$ & $9,139.310$ & $10,154.630$ \\
\hline Adj.Close & 253 & $8,598.762$ & 708.425 & $6,860.670$ & $8,098.380$ & $9,139.310$ & $10,154.630$ \\
\hline Volume & 253 & $\begin{array}{c}2,869,553,75 \\
5.000\end{array}$ & $\begin{array}{c}1,208,473,51 \\
7.000\end{array}$ & $149,410,000$ & $\begin{array}{c}1,976,770,00 \\
0\end{array}$ & $\begin{array}{c}3,824,770,00 \\
0\end{array}$ & $7,279,230,000$ \\
\hline
\end{tabular}

Table 3 Summary of Statistics for Nasdaq

\begin{tabular}{|c|c|c|c|}
\hline & \multicolumn{3}{|c|}{ Dependent variable: } \\
\hline & Luckin Coffee & Nasdaq & Starbucks \\
\hline & (1) & (2) & (3) \\
\hline \multirow[t]{2}{*}{ after_news } & $-24.596^{\star \star \star}$ & $767.558^{\star \star \star}$ & $-10.561^{\star \star \star}$ \\
\hline & (1.132) & (89.726) & $(1.071)$ \\
\hline \multirow[t]{2}{*}{ Constant } & $28.592^{\star \star \star}$ & $8,472.708^{\star \star \star}$ & $87.097^{\star * *}$ \\
\hline & $(0.561)$ & $(44.417)$ & $(0.53)$ \\
\hline Observations & 253 & 253 & 253 \\
\hline $\mathrm{R} 2$ & 0.653 & 0.226 & 0.279 \\
\hline Adjusted R2 & 0.651 & 0.223 & 0.276 \\
\hline Residual Std. Error (df = 251) & 7.748 & 613.860 & 7.326 \\
\hline F Statistic (df = 1; 251) & $471.696^{\star \star \star}$ & $73.179 * \star \star$ & $97.267^{\star * *}$ \\
\hline Note: & ${ }^{*} p^{\star \star} p^{\star \star \star} p<0.01$ & & \\
\hline
\end{tabular}

Table 4 Regression Results

\begin{tabular}{|c|c|c|c|c|c|c|c|}
\hline Statistic & $N$ & Mean & St. Dev. & Min & Pctl(25) & Pctl(75) & Max \\
\hline Open & 253 & 83.608 & 8.994 & 55.550 & 77.250 & 89.900 & 98.140 \\
\hline High & 253 & 84.509 & 8.612 & 57.440 & 78.040 & 90.440 & 99.720 \\
\hline Low & 253 & 82.466 & 9.461 & 50.020 & 76.200 & 89.170 & 97.210 \\
\hline Close & 253 & 83.515 & 8.970 & 56.330 & 77.450 & 89.920 & 99.110 \\
\hline Adj.Close & 253 & 82.671 & 8.562 & 56.013 & 77.100 & 88.458 & 97.239 \\
\hline Volume & 253 & $\begin{array}{c}9,393,731.0 \\
00\end{array}$ & $\begin{array}{c}5,204,788 . \\
000\end{array}$ & $1,847,800$ & $5,859,200$ & $11,184,500$ & $28,770,600$ \\
\hline
\end{tabular}




\section{CONCLUSION}

I did summaries of statistics for Luckin, Coffee, Starbucks, and Nasdaq, and find that the volatility of Luckin Coffee is higher than Starbucks and Nasdaq, which is due to the impact of the scandal event. I also did time series plots of Luckin Coffee, Starbucks, and Nasdaq; the result shows that Luckin Coffee had a Lshape dip that never recovered due to the fraud event. On the other side, Nasdaq and Starbucks have a similar track; both had a dip from early March to the mid-March, that is potentially caused by the hit from COVID-19. The regression analysis shows that although Luckin Coffee was severely affected by the scandal event, Nasdaq and Starbucks had limited impact from this event, which means that the dip of Luckin Coffee's stock price was not strong enough to affect the whole market, even though it had a slight impact on Starbucks' stock price.

However, there are still some limitations that should be adjusted. First, this research does not involve in any textual analysis, which is a potential issue of missing out important information. In addition, it is also possible that other fraud events did not have such a big impact on the stock prices; the research is focusing on a narrow view of the impact of news on stock prices. Therefore, for the improvement of this research, I will add more comprehensive analysis such as textual analysis and computational linguistic method. Furthermore, it is also better to look at the impact of news in a wider range, instead simply looking at one firm and its competitor.

\section{REFERENCES}

[1] J. Boudoukh, R. Fieldman, S. Kogan, M. Richardson. Which news moves stock prices? A textual analysis. No. w18725. In: National Bureau of Economic Research, 2013. DOI: $10.3386 / w 18725$

[2] W. Antweiler, and M. Z. Frank. Is all that talk just noise? The information content of internet stock message boards. In: The Journal of finance 59.3. 2005, DOI: http://doi.org/10.1111/j/15406261.2004.00662.x.

[3] W. S. Chan. "Stock price reaction to news and nonews: drift and reversal after headlines." In: Journal of Financial Economics 70.2. 2003. DOI: http://doi.org/10.1016/S0304-405X(03)00146-6

[4] J. Wong. A Rival to Starbucks in China Brews Up a Frothy IPO. The Wall Street Journal. 2019.

[5] J. Werneu and J. Jargon. Starbuck fights hot startup in China. The Wall Street Journal. 2019.

[6] J. Wong. What Investors Can Learn from Luckin' s Caffeine Crash. Wall Street Journal. 2020.
[7] A. Lucas and L. Picker. Starbucks' China challenger Luckin Coffee prices IPO at \$17 a share. CNBC. 2019. 